\title{
Hermenêutica e narrativa: a experiência de mães de crianças com epidermólise bolhosa
} congênita*

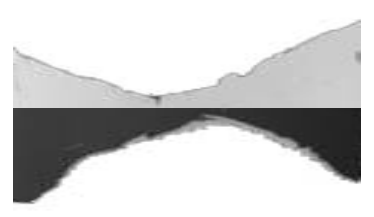

Andrea Caprara ${ }^{1}$

Maria do Socorro Castro e Veras ${ }^{2}$

CAPRARA, A.; VERAS, M. S. C. Hermeneutics and narrative: mothers' experience of children affected by epidermolysis bullosa, Interface - Comunic., Saúde, Educ., v.9, n.16, p.131-46, set.2004/fev.2005.

The paper analyses the narrative of three mothers of children affected by Epidermolysis Bullosa (EB), adopting an approach inspired by the phenomenological hermeneutics of P. Ricoeur. Epidermolysis Bullosa is a severe and rare disease affecting mostly the skin and mucosae, producing deep skin troubles and suffering to the children affected and the family members involved in caring for him or her. Experience of suffering, stigma, fear of contagion, relation with health professionals, particularly medical doctors, care practices, are some of the issues that have been considered in the paper. The exchange of experiences promoted by social networks can improve the quality of life of EB patients as well as providing social support to family members. Moreover, the improvement of this movement can stimulate health professionals and health managers to adopt more effective and equitable public policies.

KEY WORDS: Hermeneutics; narrative analysis; epidermolysis bullosa.

Analisam-se os discursos de três mães de crianças portadoras de Epidermólise Bolhosa (EB) congênita, com uma abordagem inspirada na hermenêutica fenomenológica de P. Ricoeur. A Epidermólise Bolhosa é uma grave e rara doença que se manifesta na pele e mucosas que, ao serem afetadas, produzem rupturas e sofrimentos para as crianças portadoras e os familiares diretamente envolvidos com o cuidado. A experiência do sofrimento, o estigma, o medo do contágio, a relação com os profissionais de saúde e em particular com os médicos, as práticas de cuidado, são alguns dos principais temas analisados. A troca de experiências promovidas por redes sociais pode proporcionar avanços na melhoria da qualidade de vida dos portadores de EB, além de apoio social para familiares e, pela expansão destas redes, sensibilizar profissionais de saúde e gestores para a adoção de políticas públicas efetivas e eqüitativas.

PALAVRAS-CHAVE: Hermenêutica; análise de narrativa; epidermólise bolhosa.

\footnotetext{
* Texto apresentado no Simpósio de Ciências Sociais e Humanas em Saúde da ABRASCO, realizado na UERJ em maio de 2004, com o título: A experiência de mães de crianças com Epidermólise Bolhosa Congênita: uma análise das narrativas.

${ }^{1}$ Professor, Departamento de Saúde Pública, Universidade Estadual do Ceará, UECE. <a.caprara@flashnet.it> ${ }^{2}$ Odontóloga, Grupo de Pesquisa: Educação, Saúde e Humanidade, Universidade Estadual do Ceará, UECE. <socorro.veras@ig.com.br>
} 


\section{Introdução}

Este artigo pretende analisar os discursos de três mães de crianças portadoras de Epidermólise Bolhosa (EB) congênita ${ }^{3}$, com uma abordagem inspirada na hermenêutica fenomenológica de P. Ricoeur e na leitura sucessiva, deste autor, feita por René Geanellos (1998a, 1998b, 2000), Inger Ekman (Ekman et al., 2000) e Lena Wiklund (Wiklund et al., 2002), na área das ciências da saúde. A Epidermólise Bolhosa é uma grave e rara doença que se manifesta na pele e mucosas que, ao serem afetadas, produzem rupturas e sofrimentos para as crianças portadoras e os familiares diretamente envolvidos com o cuidado. As crianças necessitam, desde o nascimento, de um cuidado contínuo por parte das mães, que terão que reorganizar completamente suas atividades diárias. As histórias apresentadas neste trabalho são de mães cearenses, duas residentes na cidade de Fortaleza e uma nascida e residente na região do sertão central do Ceará que, ao vivenciarem a experiência comum de terem filhos portadores de $E B$, têm a oportunidade de contribuir para a compreensão do processo de sofrimento ligado a esta grave e rara doença. Apropriada para esses casos, a pesquisa narrativa adquire um significado importante, pois permite verbalizar a história colocada no centro do interesse da pesquisa. Por ser a narrativa uma projeção, e estando em continuidade com a vida individual, reflete o cotidiano de cada um de nós, permitindo a exteriorização de esquemas e emoções internas.

Nos últimos anos tem sido desenvolvida a análise de narrativas na pesquisa qualitativa na área da saúde, inspirada nas premissas filosóficas da fenomenologia, da hermenêutica e do existencialismo. Estas premissas constituem as bases de diferentes abordagens (Geanellos, 2000; RobertsonMalt, 1999; Todres \& Wheeler, 2001). Por fenomenologia entende-se a corrente filosófica elaborada por Husserl, que parte das situações experienciadas pelos sujeitos. Esta corrente se desenvolveu nos primeiros anos de 1900 e depois da conferência de Husserl em Paris em 1929, sua influência estendeu-se em toda Europa (Pinto, 1998). Por existencialismo, termo desenvolvido nos anos trinta do século 20, designa-se a corrente filosófica que aborda a natureza do Dasein, existência humana cotidiana, de ser no mundo (Dreyfus, 1991). A temática existencialista desenvolvida na Europa depois da $1^{\text {a }}$ Guerra Mundial, considerada "renascimento kierkegaardiano", e a análise existencialista de K. Jaspers e M. Heidegger influenciaram J. P. Sartre, M. Merleau-Ponty e Simone de Beauvoir, na França. O termo hermenêutica, na filosofia grega, expressa a arte de interpretar. Com o passar do tempo adquiriu um significado mais amplo, indicando, no âmbito filosófico, diversas formas de teoria da interpretação. Os filósofos que pertencem a esta linha de pensamento se ocupam da existência humana, não do ponto de vista da observação, mas da reflexão filosófica. Nesta perspectiva, o homem é considerado não somente enquanto organismo biológico, mas algo mais, assim como a medicina é considerada algo mais do que a ciência natural (Caprara, 2003).

Ao centro da abordagem hermenêutica está a compreensão do texto, procurando entender a multiplicidade dos significados, tentando clarear o que é confuso, escondido, fragmentado (Ricoeur, 1991; 1995). Por meio 
do processo interpretativo, segundo Ricoeur, não se procura identificar as intenções do autor, mas entender os sentidos do texto, propiciando o desenvolvimento do conhecimento intersubjetivo. Por meio do conceito de "fusão dos horizontes", Gadamer tem modificado a perspectiva hermenêutica porque para ele o significado não está no texto nem no autor, mas na relação que existe entre eles (Gadamer, 1997). Neste sentido, a perspectiva narrativa é dialógica: Mishler (1986), por exemplo, critica o fato que exista uma relação entre o pesquisador e a pessoa entrevistada, um objeto a ser conhecido; este autor fala de pessoas em relação entre elas quando afirma que não estamos entrevistando alguém, mas aprendendo dele. Para Mishler, então, não podemos separar as respostas das perguntas e do contexto.

Segundo Alves \& Rabelo (1999) a experiência da enfermidade é entendida como: "a forma pela qual os indivíduos situam-se perante ou assumem a situação de doença, conferindo-lhe significados e desenvolvendo modos rotineiros de lidar com a situação" (p.171). Eles complementam também que: "as respostas aos problemas criados pela doença constituem-se socialmente e remetem diretamente a um mundo compartilhado de práticas, crenças e valores" (Alves \& Rabelo, 1999, p.171). O que nos interessa é compreender a dinâmica cotidiana das interações que vivenciam as mães de portadores de EB, os fatores psicossociais relacionados à experiência, bem como os mecanismos de adaptação e superação à doença dos filhos.

Neste trabalho procura-se entender o significado da experiência de vida mediante as narrativas analisadas enquanto texto. As palavras vão surgindo nos discursos de acordo com os temas colocados e revelam o mundo de cada uma delas em torno da experiência de ser mãe de portador de EB. Na primeira parte apresentaremos a abordagem teórico-metodológica escolhida, e em seguida, alguns conhecimentos essenciais sobre a EB. Na terceira parte, abordaremos o contexto histórico e social das histórias apresentadas, e na quarta e última parte, a análise das narrativas.

Abordagem teórico-metodológica

Para Ricoeur, a interpretação coloca-se entre a linguagem $e$ a vida vivenciada por meio de uma série de conceitos interpretativos entre os quais o distanciamento, a apropriação, a explicação, a compreensão (Ricoeur, 1991; 1995). No distanciamento, a objetivação do texto reduz a intenção do autor, eliminando a idéia de que exista uma única forma de compreensão. Um texto tem vários significados $e$ as pessoas interpretam diferentemente o mesmo texto. O distanciamento produz a objetivação do texto libertando-o do seu autor e de suas intenções, fornecendo uma vida própria (Geanellos, 1998a). O distanciamento não é imposto metodologicamente, ao contrário, é um aspeto constitutivo da sua transformação em texto escrito por meio da fixação da língua falada em língua escrita (Ricoeur, 1991; 1995). Um outro conceito é representado pela apropriação, quando o intérprete apropria-se do significado de um texto, transformando este em algo familiar, próprio. A apropriação do significado do texto é similar ao sentimento de pertença a uma tradição (Geanellos, 1998 a; 1998b; Wiklund et al., 2002 ). O processo interpretativo pode ser representado em algumas etapas principais como a vida vivenciada expressa por meio da linguagem, recolhida mediante entrevistas, transcrita em 
textos e interpretada (Geanellos, 2000).

Seguindo este processo metodológico, inicialmente foram feitas freqüentes visitas, por parte de um dos autores, nas casas das mães com filhos portadores de EB, participando das práticas de cuidado, observando e anotando as atividades diárias. Depois deste conhecimento inicial e vida compartilhada, realizamos, com as mães, as entrevistas gravadas em fitas de áudio $e$ transcritas. Sucessivamente elaboramos uma primeira interpretação superficial dos textos, por meio de leituras múltiplas, para entender o conteúdo nas suas linhas gerais e identificando alguns temas principais como a experiência do sofrimento, o estigma e o medo do contágio, a relação com os profissionais de saúde e em particular com os médicos, as práticas de cuidado. Em seguida, tentamos analisar os temas principais explicitando nossas pré-compreensões, evidenciando como as interpretações são influenciadas por estas, abrindo um diálogo com os autores que abordaram estes conceitos (Ricoeur, 1995). As précompreensões são discutidas com a estrutura teórica e os principais conceitos. Podemos citar, por exemplo, Erwin Goffman (1983) e o conceito de estigma, a relação médico-paciente tal como abordada por Gadamer (1994) e Balint (1988), a ética do cuidado elaborada por Leonardo Boff (1999).

Em uma fase sucessiva tentamos construir um diálogo entre nós, pesquisadores, sobre as experiências individuais perante fatos comuns, identificadas nos fragmentos dos discursos, e a abordagem teóricometodológica escolhida. Tentamos analisar as unidades de significação, assim como descrito por Ekman et al. (2000), representadas por pequenos fragmentos de discurso, subtemas mais profundos que se expressam, por exemplo, por meio das metáforas e outras figuras de estilo narrativo. Nesta fase procuramos entender as relações entre as partes do texto e o todo. Este processo pode ser representado em forma de espiral que passa do geral ao particular e vice-versa.

\section{Epidermólise bolhosa}

O termo epidermólise bolhosa (E.B) inclui um grupo de doenças caracterizado pela tendência a produzir vesículas na pele e em algumas vezes nas membranas mucosas. As vesículas e bolhas, usualmente, se desenvolvem após pressão mecânica ou fricção, mas podem ocorrer espontaneamente (Braun-Falco et al., 1991). A pele é constituída por várias camadas ligadas entre si por fibras protéicas de colágeno. Na E.B., estas fibras de união não funcionam eficazmente, com isso as várias camadas de pele se separam facilmente. $\mathrm{O}$ espaço que se forma entre as camadas é preenchido por soro ou por fluido rico em proteínas, surgindo, assim, uma bolha (Diniz \& Vieira, 1995).

A Epidermólise Bolhosa Congênita representa um grupo heterogêneo de patologias de caráter genético caracterizado pela formação de bolhas na região cutâneo-mucosa, após trauma mínimo, como resultado de fragilidade do epitélio. Mais de vinte subtipos têm sido descritos, de acordo com o tipo de padrão genético, distribuição regional das lesões e aparência individual destas, presença ou não de atividade extracutânea e achados ultraestruturais $e$ imunohistoquímicos. Estes subtipos são divididos em três categorias: EB simples, EB juncional e EB distrófica (Eady, 1990; Fine, 1999). Dependendo da formação de posteriores cicatrizes e conseqüentes atrofias, Braun-Falco et al. 


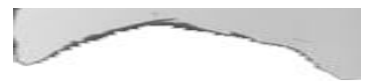

(1991) classificaram as EB como distróficas e não-distróficas. A problemática da nomenclatura complicou-se ainda mais face à doença designada de epidermólise bolhosa adquirida, afecção não integrável neste grupo porque não apresenta determinação genética e é provavelmente de natureza auto-imune (Diniz \& Vieira, 1995).

O grupo das EB distróficas é dos que impõem restrições mais severas e é especialmente significativo, pois requer adaptações sociais e educacionais a seus portadores, visto que a separação das camadas localiza-se abaixo da junção da epiderme com a derme, onde se encontram vasos sangüíneos e nervos. Deste modo, as bolhas podem ser profundas, dolorosas e com sangue. Algumas bolhas são mais superficiais. As unhas têm tendência a deslocar-se e a cair. Infelizmente, na EB distrófica, as bolhas tendem a aumentar de volume. Usualmente, procede-se a sua abertura para tentar reduzir seu crescimento, esvaziando, assim, seu conteúdo. Isto origina uma ferida, que pode cicatrizar satisfatoriamente, mas que, com freqüência, infecta, causando problemas. As crianças referidas nesse estudo são portadoras desse tipo de EB. Tarefas simples, como engatinhar, caminhar, utilizar determinados tipos de roupas ou sapatos demandam esforços suficientes para provocar a formação de bolhas. As bolhas de maior profundidade formam cicatrizes que têm a aparência de uma queimadura. As repetidas cicatrizes levam a complicações como a pseudosindactilia, condição na qual o crescimento das cicatrizes causa a perda do movimento dos dedos do paciente, evoluindo para uma distrofia, especialmente nas mãos (APPEB, 2000).

O tratamento é multidisciplinar e nenhum tipo específico de terapêutica existe. Deve-se evitar traumas cutâneo-mucosos, observar escrupulosas condutas de higiene dos cuidadores e do lar; as infecções secundárias devem ser tratadas com antimicrobianos tópicos e/ou sistêmicos e a dieta rica em proteínas, ferro e zinco. Acompanhamentos psicológicos, nutricionais, odontológicos, fisioterápicos, hematológicos, enfim integrais são fundamentais para a melhoria da qualidade de vida dos acometidos (Fine et al., 1999a). Diniz E Vieira (1995) relatam que o nascimento de uma criança com EB afeta profundamente a família e acarreta conseqüências de ordem psíquica $e$, ainda, que a condição econômica desfavorável agrava inevitavelmente a situação. George (1988) constatou tal afirmação em relato de experiência na Nigéria.

Nos Estados Unidos existe um registro nacional de EB, o National Epidermolysis Bullosa Registry (NEBR), que estima a incidência em, aproximadamente, vinte casos de EB em um milhão de nascidos vivos (Fine et al., 1999b). O NEBR foi criado em 1986, para informação epidemiológica, acompanhamento e identificação de casos de EB. A exemplo disto, outros países também têm seus registros, como Noruega, Japão, Croácia, Suécia (Fine et al., 1999b). No Brasil não há um registro nacional e a estimativa não pode ser feita.

\section{O contexto social}

Buscando entender como se dão as relações das mães envolvidas no estudo com o mundo, no jogo das relações sociais, em termos de habilidades, flexibilidade $e$ adaptações às mudanças, busca-se como sugerem Gomes et al. (2002) promover uma compreensão das vivências da doença ao situar as expressões 
dos sujeitos no contexto em que tais aspectos foram produzidos; fazer uma releitura de suas posições em face da doença; fazer inferências para se articular o vivido e o experado da doença presente no cotidiano e interpretar os sentidos para compreender as regras constitutivas das particularidades inerentes à doença vivenciada. As crianças são portadoras de Epidermólise Bolhosa Distrófica Recessiva, um dos subtipos raros. Somente uma dessas crianças tevi o diagnóstico confirmado laboratorialmente e as outras tiveram o diagnósticc clínico confirmado pelas características das lesões. Sem privilegiar individualidade ou condições destas e, para resguardar a identidade $e$ privacidade das famílias, trocamos os nomes das mães. Em razão da religiosidade católica professada, as mães entrevistadas são aqui identificadas como Assunção, Conceição e Fátima, em alusão às santas de devoção do povo cearense. Todas as entrevistadas foram estimuladas para contar a própria experiência da doença.

Partiu de Fátima a iniciativa de aproximação dessas mães; embora Conceição e Assunção não se conheçam pessoalmente, por morarem em cidades distantes, as três compartilham experiências entre si, sendo Fátima o ponto de contato entre elas. Mesmo apresentando algumas características comuns, o discurso de cada uma é próprio e as trajetórias individualizadas de acordo com aspectos sociais, econômicos e culturais de cada família.

Assunção é casada com um primo e nunca tinha ouvido falar da doença até o nascimento da primeira filha. O casal tem duas filhas, hoje com 18 e dez anos, portadoras de EB. A família mora em um bairro da zona norte de Fortaleza. A mãe é professora licenciada para acompanhamento das filhas e o pai é autônomo. As irmãs, com o passar dos anos, apresentaram lesões em várias partes do corpo e têm seqüelas, como contraturas digitais (freqüentes nos portadores de EB), acarretando déficit funcional das mãos. Porém não foi impedimento para que elas aprendessem a ler e escrever, tendo sido alfabetizadas em casa. A maior limitação, hoje, é a presença de extensas lesões, que as mantém, na maioria das vezes deitadas e isoladas de contatos externos, e que requerem o uso contínuo de pomadas antibióticas e lubrificantes (isolantes) em todo o corpo, além das lesões de mucosa que dificultam a alimentação. O uso de roupas, por vezes é inviável devido à extensão $e$ localização das lesões. Contudo, as irmãs se locomovem sozinhas, assistem aula em casa, gostam de brincar de boneca, maquiagem e fazem pintura em papel e tecido brilhantemente, além de gostarem de passear como a maioria das meninas de igual idade. Elas aguardam, ansiosamente, o passeio anual ao shopping para ver a decoração natalina. A família tem o apoio profissional do mesmo pediatra desde o nascimento da primeira filha, e parte da medicação é doada pela Secretaria de Saúde do Estado. O benefício do Instituto Nacional de Seguridade Social (INSS), conseguido em 2002, auxilia na aquisição de outros medicamentos e alimentação adequada para as irmãs. Antes da concessão do benefício, por algumas vezes, Assunção percorreu jornais e emissoras de televisão, pedindo ajuda financeira, tendo recebido doações de medicamentos, alimentos, produtos de limpeza. Até hoje, algumas pessoas ainda ajudam neste sentido. Assunção, sendo católica praticante, vai às missas todo dia 13 (alusivas a N. Sra. de Fátima), ensina e transmite às filhas sua formação católica, tendo realizado, com grande emoção, os rituais sacramentais da igreja católica, o 
batismo e a primeira comunhão das meninas.

A família de Conceição mora na zona rural de uma cidade do sertão central cearense, distante duzentos $\mathrm{km}$ da capital e a três $\mathrm{km}$ da sede do município, em uma fazenda, na qual o pai é empregado. $O$ casal tem quatro filhos, não tem laços de parentesco, e o terceiro é portador de EB. Aos quatro anos, apresenta sinéquias nos pés, movimenta-se pela casa de velocípede ou arrastando-se e, de um modo geral, desenvolve-se bem. Conceição, por tentativas, descobriu que a melhor forma de seu filho não se machucar era vaselinando-o e enrolando-o com bandagens e em seguida vestindo-o normalmente. São feitas três trocas diariamente e, como na casa de Assunção, há sempre muitas roupas e lençóis para lavar e engomar, o que Conceição faz sempre com um sorriso contagiante. Percebe-se nela, alegria em todos os momentos do cuidado com a criança, só rompida pela preocupação com o fato de ele ainda não andar. Mas, logo supera ao lembrar que sua mãe relata ter tido "umas feridas como as do seu filho" e hoje, é sadia. Com o benefício do INSS que o filho recebe, Conceição compra remédios, fraldas descartáveis e, como ela costuma dizer, brincando, "mais sabão do que comida”. Como Conceição é a principal responsável pelos cuidados com o filho, ela não tem oportunidade de freqüentar a igreja na cidade, mas percebe-se sua devoção aos santos católicos, espalhados pela casa, pelas inúmeras vezes em que roga proteção e agradece as graças diárias.

Fátima e seu marido desconheciam qualquer caso de EB na família, até o nascimento de sua filha. Para o casal foi um momento angustiante, nos primeiros dias, pela inabilidade de cuidar de uma criança susceptível a traumas ocasionados por eles próprios em momentos, aparentemente, corriqueiros, como a troca de fraldas. $\mathrm{O}$ ato de acariciar ou pegar ao colo um bebê com EB requer medidas de segurança, como retirar jóias, alianças, roupas com botões ou zíperes que possam, inadvertidamente, machucar a criança. Como as outras mães, uma dificuldade inicial era quanto ao uso de roupas, após várias tentativas e bolhas, optaram por deixá-la desnuda e vaselinada, dessa forma o contato era mais suave $e$ as lesões mais escassas. Também adotaram o que poderia se chamar "manipulação mínima", assim a criança era tocada o mínimo possível e somente era retirada do berço na hora dos banhos; na tentativa de suprir a falta de contato, procuravam falar o máximo com a criança, para que ela experimentasse outra forma de carinho, como a pediatra recomendava e, também, a apostila da Associação Alemã para Epidermólise Bolhosa (s/d). Os pais percebiam que ela conhecia vozes e músicas repetidas. Com o passar dos meses e a contínua aprendizagem, Fátima se sentia cada vez mais capaz de cuidar da filha e cultivava a esperança de vencer, com ela, as dificuldades do cotidiano. Apesar de todos os esforços, a criança faleceu aos sete meses, em casa, na hora do banho, nos braços de Fátima.

\section{Análise das narrativas}

\section{Os temas principais}

Após essa breve construção biográfica, buscamos, nos fatos comuns da vivência relatada, compreendê-los, contudo sem esquecer que essas experiências singulares nos revelam um processo contínuo contextualizado pelas interações social, cultural e econômica, por vezes alterado pela doença. 
O nascimento: a relação com a biomedicina $e$ a dimensão religiosa

A respeito do nascimento, momento de expectativa para a maioria das mães, geralmente traduzido por perguntas sobre a morfologia dos filhos, para as três entrevistadas foi um momento marcado pela dúvida, pois as explicações iniciais sobre a doença não foram suficientemente esclarecedoras, estabelecendo um quadro de preocupação $e$ incerteza sobre o futuro de seus filhos como, por exemplo, nesses três depoimentos:

....eu a vi , ainda na sala de parto, e achei estranho a pele do rosto [...] parecia que estava arranhado o nariz[...].Depois disso só a vi doze horas depois, quando o médico deu uma receita escrita na frente e costa e disse que ela tinha um problema mas ia ficar boa $e$ indicou o nome de dois especialistas para eu procurar. Só consegui marcar a consulta um mês depois[...], o médico era muito procurado e bom. Ele explicou tudo e mandou fazer uma biópsia já me informando que poderia dar um resultado ruim, entreguei a Deus[...]. Quando recebi o resultado, ele disse que seria muito difícil e que talvez ela não completasse um ano, de novo me vali de Deus e fiz uma promessa de que amanheceria em Canindé $e^{4}$ no dia do seu primeiro aniversário... (Assunção)

....ele nasceu sem pele no pé e disseram que era a mesma doença da filha do (...), daí fiquei mais calma porque pelo menos já sabiam o quê era[...]. Fui encaminhada para Fortaleza e lá o médico e, um bocado de estudantes olhando, disse que era muito grave e que ele não passava de vinte dias[...]..e eu estava com três dias do resguardo, chorei muito[...] e, quando eu estava em uma sala sozinha um estudante me acalmou dizendo que eu confiasse em Deus... (Conceição)

...na hora que ela nasceu, a médica mostrou-me suas mãozinhas, parecia que estavam com queimaduras nos dedos e no queixo também tinha uma lesão, depois ela levou-a para a UTI, porque ela estava 'gemente'[...]. Pouco tempo depois do parto, a médica conversou conosco, eu e meu marido, sobre o diagnóstico e pediu que chamássemos um especialista para confirmação $e$ acompanhamento. Nós passamos a noite meio acordados e nos questionamos até como ela iria escrever com as mãos daquele jeito. Apesar de um pronto diagnóstico da doença parecia que nós não tínhamos a dimensão do problema nas primeiras horas... (Fátima)

O relato de Conceição conduz a reflexão sobre a relação médico-paciente $e$ aponta a não-observância do contexto social pelo profissional ao referir tão delicado assunto, revelando a necessidade de humanização da prática médica assim como descrito por Caprara \& Silva Franco (1999). Tal problemática é levantada por Morais (1997) ao criticar o ensino da Medicina no qual não existe tempo para perder com análises sobre a interdependência das relações, 
fragmenta-se o corpo e passa-se a compreender as partes, desmembrando o indivíduo, descontextualizando-o. Ao que Klafke (1991) reforça afirmando que poucas são as disciplinas que tratam do aspecto emocional do paciente, como também do aluno.

Diante de um problema genético, os membros das famílias envolvidas são chamados a recordar sobre casos semelhantes e somente Conceição relata uma história que lembra EB: "Minha mãe conta que teve essas mesmas feridas até a idade de dez anos e depois ficou boa [...] ela disse que nasceu assim porque a mãe dela comeu uma carne de porco quando estava grávida...".

Ela reporta à narrativa da mãe e, mesmo conhecendo a versão biomédica da doença, refere-se a causalidade ligada a cultura popular, até porque ela traz um alento e perspectiva de cura vivenciado por uma pessoa de sua confiança.

$\mathrm{Na}$ cidade onde Conceição vive e da qual o marido de Fátima é natural, são conhecidos outros casos relatados na história oral dos moradores; sendo comum o casamento entre consangüineos no interior cearense, é provável que se trate de casos de EB que não sobreviveram ou não foram diagnosticados. Em 2000, nasceu outra criança com EB na cidade onde Conceição vive. Esta criança foi transferida em seguida para Fortaleza, vindo a falecer com um mês de vida.

$\mathrm{O}$ aconselhamento genético tem implicações de ordem médica, ética $e$ psicossocial, que se refletem nas definições atribuídas a este processo (Silva $\varepsilon$ Ramalho, 1997). Estas mães tiveram acesso às informações de ordem genética, mas nenhum apoio psicológico profissional para o enfrentamento e convivência com a doença, buscando na religiosidade a maior fonte de força para a superação dos problemas decorrentes.

O cuidado

A principal responsável pelo cuidado nessas famílias é a mãe, e ela busca conciliar as tarefas de dona de casa e cuidadora, ao manter a ordem familiar e zela pelo filho doente e suas demandas. As mães sintetizam as alterações do cotidiano familiar na dedicação quase que exclusiva aos seus filhos portadores de EB. Evidencia-se nestes fragmentos de discurso uma carga emocional muito grande e destaca-se uma unidade de significação presente em várias partes da narrativa: a fé. Esta é sempre presente seja como forma de aceitação e conformação, seja como fonte de forças para enfrentar as dificuldades e limites da doença, nos processos de cuidados paliativos e/ou curativos. Essas mães, atualmente ou em algum momento de suas vidas, pagaram promessas feitas pedindo a saúde de seus filhos, seja freqüentando missas, usando determinadas roupas ou fazendo alguma abstinência alimentar, buscando, dessa forma, a solução para o conflito.

Relatando as alterações do cotidiano familiar após o nascimento dos filhos com EB, as mães tomam a posição de principais cuidadoras:

Eu estou afastada do meu trabalho para me dedicar a elas [...]. A luta é muito grande e é porque minha mãe ajuda muito... (Assunção)

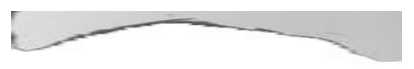

Eu passo o dia cuidando dele e da casa [...]que tem que ser muito limpa para não dar infecção[...].Os outros filhos têm que compreender que ele precisa de mais atenção, mas eu tento fazer o possível... (Conceição) 
Enquanto ela esteve conosco, meu marido teve que trabalhar mais ainda para compensar o tempo que eu fiquei sem trabalhar[...]. Foi um período intenso, mas não cansava[...] por mim estava bem e eu agradecia a Deus cada dia que acordávamos juntas... (Fátima)

\section{O estigma}

A curiosidade e o receio de contágio, por vezes, superam as relações de cooperação e solidariedade humanas, criando tensões entre as pessoas, como nos relatos seguintes.

....com minha família nunca tive problemas[...], uma vez nós fomos a um shopping e eu notei que uma pessoa fechou o nariz quando nós entramos na loja, foi o quê mais me chocou[...], mas eu procuro esquecer e peço a Deus que perdoe essa pessoa. (Assunção)

....no começo foi difícil[...], hoje todo mundo sabe que não 'pega', mas fere a gente ver as pessoas se afastando da nossa casa por medo[...]. Se um dia eu sair daqui (zona rural, com vizinhos a mais de duzentos metros), não quero morar na cidade para não ser alvo de curiosidade do povo ... (Conceição)

...nós só saíamos para ir para a médica e mesmo assim em horários que não tivessem outras crianças (para protegê-la do contato com crianças doentes), mas nas poucas vezes que encontrávamos com pessoas no elevador sempre chamava atenção a condição de sua pele despertando curiosidade e indiscrição... (Fátima)

\section{As redes de solidariedade}

Em 2000, a exemplo de outros países, foi criada em Brasília a Associação de Parentes, Amigos e Portadores de Epidermólise Bolhosa Congênita (APPEB, 2002), cuja intenção é localizar os demais portadores de EB para ajudar a conviver melhor com o problema, por meio da troca de experiências, uso de medicamentos e alimentação adequada e conseguir médicos e profissionais de saúde dispostos a estudar a doença para orientar as famílias e os portadores, como também sensibilizar o Poder Público para a atenção integral deste grupo. Em Minas Gerais, outra associação também foi fundada (Ampapeb). As mães entrevistadas também apresentaram interesse em reunir-se e articular uma associação local, a partir da simetria dos interesses têm a vontade do aprendizado recíproco, mostrando-se solidárias.

...eu gostaria de conhecer outras pessoas, não porque eu quero que tenha mais criança doente, é só pra conversar, até ajudar[...].As meninas ficaram felizes quando viram uma fita que tinha outras crianças iguais a elas [...]. Quem sabe uma associação dessas crianças.... (Assunção).

Eu soube da filha do (...), mas fiquei muito triste quando ele disse que ela morreu [...]. Minha irmã, em São Paulo, diz que conhece

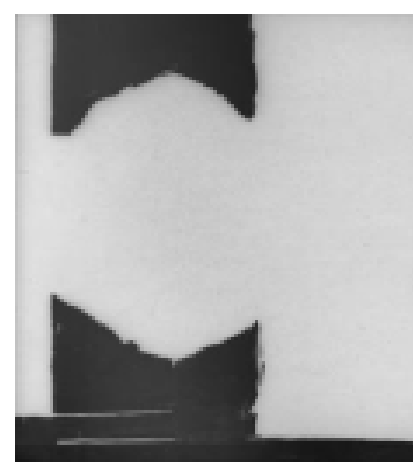


outras crianças assim [....], no ano passado nasceu uma criança aqui e foi para Fortaleza, não durou um mês... (Conceição)

Quando (...) nasceu, nós nunca tínhamos ouvido falar de EB, mas apesar de rara, quando ela foi internada aos 40 dias, havia no hospital uma outra menina, um mês mais velha que ela, com EB [...], na sala de espera da UTI, nós trocávamos experiências com os pais dela e aprendemos muito com eles [...] alguns médicos e auxiliares não conheciam, até então, como manipular estas crianças [...]. Esta criança faleceu aos quatro meses, mesmo sabendo das individualidades de cada uma, tive medo [...], também tenho cuidado ao aproximar-me de outros portadores, porque temo que minha experiência possa ser desestimulante para outras famílias... (Fátima)

A fita que Assunção relata ter assistido é uma produção da DebRA (Dystrophic Epidermolysis Bullosa Research Association of América, Inc.) e apresenta crianças americanas portadoras e depoimentos dos pais sobre a convivência com a doença.

Um exemplo positivo de organização para garantir o cumprimento da Constituição Federal, no tocante ao direito à assistência social, é relatado por Assunção:

A primeira vez que soube que elas tinham direito foi numa campanha que eu fui pedir auxílio na televisão[...] há muito eu tentava um auxílio do governo e só consegui quando após cinco anos o CEDECA-CE (Centro de Defesa da Criança e do Adolescente - secção Ceará) entrou na Justiça, mesmo assim eles disseram que eu não conte com essa ajuda porque, às vezes, suspendem sem nem avisar e tem que começar tudo de novo [...].

Para Durham (1984), a emergência das reivindicações está associada à agudização de uma carência que provoca uma fragilização sistemática das condições de vida num determinado momento e para determinados atores sociais, assim a passagem do reconhecimento da carência para a formulação da reivindicação é medida pela afirmação de um direito, que começa a ser construído por novas representações.

O desenvolvimento das redes de solidariedade humana, enquanto redes de indivíduos alternativas ao individualismo, propicia a articulação entre grupos pela conquista de direitos básicos contribuindo para o processo de democratização da sociedade.

As necessidades de saúde se apresentam de várias formas e exigem ações intersetoriais que se caracterizam pela co-responsabilidade dos diferentes setores governamentais, não-governamentais e da sociedade civil, no sentido do desenvolvimento humano e da qualidade de vida como abordam Marmot $\&$ Wilkinson (1999). No modelo governamental de atenção à saúde, alcançar a integralidade proposta requer o compromisso multissetorial com a eqüidade a partir da garantia de acesso a todos os níveis de atenção.

As mães (re)constróem a história, não como de sofrimento ou dor, mas com 
profundo sentimento de esperança e fé, em que as limitações e dificuldades cotidianas são superadas nos momentos da realização dos sonhos possíveis. Nisso, elas expressam que as dimensões física, emocional e espiritual estão presentes, integralizadas, nas festas e acontecimentos sociais da cultura de cada uma delas, levando em diante projetos e sonhos para que não fossem excluídas do mundo social.

As meninas esperam ansiosas, como toda criança, o dia do aniversário, o das crianças, o Natal [...]. O contato com outras pessoas as deixa muito felizes [...].Elas adoram receber presentes, $e$ às vezes, vamos ao shopping, só não vamos mais porque é difícil o transporte [...]. A gente paga uma professora que vem em casa [...]. Também teve os 15 anos da mais velha com valsa e tudo [...]. Elas duas já fizeram a $1^{\text {a }}$ comunhão e foi muito bonito, na igreja.... (Assunção)

Eu tenho uma promessa pra fazer a festa de aniversário dele todo ano, e é quando eu fico mais feliz [...], o padre veio fazer o batizado dele aqui em casa. Um dia, se Deus quiser, ele vai andar... (Conceição)

Com todas as mudanças de planos por causa da doença e apesar dela nós já estávamos acostumados e eu sabia das dificuldades mas sempre pensei que venceríamos todas, juntos.[...] nós brincávamos de comemorar cada 'mêsversário' dela... (Fátima)

O diálogo entre pesquisadores, experiências individuais e abordagem teórico-metodológica

Para Ricoeur o sofrimento, quando se abate sobre alguém, é sempre solitário e inominável, o que faz de cada sofredor um sofredor, específico na sua irresolução e incomunicabilidade (Ricoeur, 1994 citado em Koury, 2002), constatado no fragmento do discurso "...só quem tem um filho com EB sabe o quanto é difícil..." .

Ricoeur (1983) apresenta o conceito de fazer experiência, inspirado em Heidegger, como sendo algo que nos sucede e atinge, nos sobrevêm, nos derruba e transforma. Nesta acepção, a palavra fazer significa suportar, sofrer, receber o que nos vem ao encontro, integrando-nos, sem implicar, que essa experiência seja efetuada em nós mesmos. A compreensão dos sentidos é sempre um confronto entre inúmeras vozes que, nas práticas discursivas do cotidiano (a linguagem em ação), apresentam-se por meio de pessoas e suas histórias de vida (Spink \& Medrado,1999).

A manifestação cutânea da doença nos remete à reflexão sobre o comportamento sociocultural ligado à EB. Na unidade de significação "...as pessoas parecem ter medo de pegar a doença, não adianta explicar que é genético." são apresentadas as tensões produzidas pelo estigma. Utilizamos o conceito de estigma de Goffman (1983) e de contágio de Czeresnia (1997) para compreender as atitudes, tendências e soluções das mães como forma de superar os limites impostos pelas concepções e o imaginário popular relativo às doenças que se manifestam na pele. Uma complexa rede simbólica liga os 
conceitos de corpo, pele, prossemia, experiência da doença. A pele, porosa, permeável, não somente aos agentes infecciosos, torna público um elemento interpretativo central por expressar a experiência dessa doença. Existe uma forte relação entre a doença contagiosa $e$ a manifestação cutânea. $O$ mesmo conceito de contágio deriva, etimologicamente, do ato de tocar: do tactum, tangere do latim. Ao mesmo tempo na história médica ocidental, uma estreita ligação tem mantido unida, entre eles, os diversos universos: aquele da manifestação na pele com o sistema nervoso central, desde a embriogênese. Muitos são os problemas psicológicos, como também de desequilíbrio da saúde que se expressam com manifestações cutâneas. Cada doença transmissível tem que ser interpretada a partir do contexto social no qual se insere porque coloca em jogo as relações dinâmicas entre os indivíduos de um grupo social. O risco do contágio, por exemplo, e os mecanismos pelos quais se produz a transmissão contribuem para a construção social da doença e produzem comportamentos que tentam separar o paciente da sociedade por meio da rejeição e do isolamento. Por exemplo, doenças como Aids e tuberculose, produzem um estigma que influencia as relações do paciente com a sociedade. Mas é a própria percepção do risco que produz aceitação ou rejeição, mesmo em casos nos quais a exata identificação do risco é imprecisa. Indeterminação $e$ ambigüidade que contribuem para a definição do estigma associado à doença foram bem descritas por Goffman (1983).

Além das reações de rejeição e de isolamento, temos de considerar elementos referentes à relação com os profissionais de saúde, em particular os médicos. Os fragmentos de discurso apresentados mostram a necessidade crescente em desenvolver uma comunicação mais aberta entre médicos e pacientes que possibilite uma maior qualidade na relação. Uma melhor relação médico-paciente não tem somente efeitos positivos na satisfação dos usuários e na qualidade dos serviços de saúde. Vários estudos mostram que influencia diretamente sobre o estado de saúde dos pacientes (Caprara \& Rodrigues, 2004). A necessidade de humanização da prática médica é evidenciada ("...só disse que ele não vivia nem vinte dias...") e permite a relação com outras abordagens teóricas (Balint, 1988; Gadamer, 1984).

Heidegger (1993) afirma que, "do ponto de vista existencial, o cuidado se acha a priori, antes de toda atitude e situação do ser humano" (p.258). Boff (1999), retoma a origem da palavra cuidado, que deriva de cogitare-cogitatus, como também de suas modificações como coyedar, coidar, cuidar, sendo, portanto o mesmo que cura: cogitar, pensar, colocar atenção, mostrar interesse, desvelo, solicitude, zelo, pois não há somente ocupação mas também preocupação e, além da intervenção, há a interação com o outro, como na unidade de significação "...eu cuido dele, dia e noite, sem cansar...", que reflete o cuidado constante e o forte envolvimento emocional da mãecuidadora.

Em pesquisa com pais de portadores de EB, Lansdown et al. (1985), concluem que esses pais necessitam, mais do que de condolências, de profissionais preparados (a despeito da raridade da doença) para superar problemas decorrentes do cotidiano e de suporte psicológico.

Todos os indivíduos com EB têm uma fragilidade, que implica alterações nas suas rotinas, notadamente na escola, no trabalho e na convivência diária, 
necessitam estar rodeados de cuidados especiais e de algumas regras proibitivas. Todos temos alguma fraqueza física e na criança com EB ela está localizada na pele, sendo apenas mais visível. Diniz \& Vieira (1995) sugerem explicar abertamente a todos os colegas, por mais jovens que sejam, exatamente o que essas crianças têm. Tais explicações evitarão comentários do tipo "que pele horrível você tem!", "isso pega-se?", "não encoste em mim, não me toque!". Se for divulgado o "fenômeno" como sendo um problema cutâneo, de origem genética e não infecciosa, ao invés de uma doença cutânea, talvez as pessoas reconheçam e mudem as atitudes, tornando-se mais positivas, realistas e estimuladoras de autoconfiança. Isto, decerto, contribuirá para o bem estar $e$ melhor integração de qualquer indivíduo, criança ou adulto com epidermólise bolhosa.

\section{Conclusões}

A teoria interpretativa de Ricoeur, escolhida para análise dos dados deste trabalho oferece múltiplos estágios de compreensão do expresso e o nãoexpresso no discurso, a interpretação simples e profunda, favorece o entendimento das partes do texto em relação ao todo e vice-versa $e$ propicia a reflexão sobre os diferentes temas surgidos a partir das entrevistas de mães de portadores de E.B congênita.

Concluímos também que a troca de experiências promovidas por redes de suporte social, mesmo que em contextos históricos e culturais diferentes, pode proporcionar avanços na melhoria da qualidade de vida dos portadores de EB, além de apoio social para familiares e, pela expansão dessas redes, sensibilizar profissionais de saúde e gestores para a adoção de políticas públicas efetivas. $\mathrm{O}$ desafio é sistematizar essas experiências na busca de incorporação de saberes visando ao respeito à vida em sua integralidade.

\section{REFERENCIAS}

ALVES, P. C.; RABELO, M. C. Significação e metáforas na experiência da enfermidade. In: RABELO, M.C.M.; ALVES, P. C.B.; SOUZA, I. M. A (Orgs.) Experiência de doença e narrativa. Rio de Janeiro: Editora Fiocruz, 1999. p.171-85.

APPEB. Associação de parentes, amigos e portadores de epidermólise bolhosa congênita. Brasília, 2002. Disponível em: <http:www.appeb.hpg.com.br>. Acesso em 14 mar. 2002.

ASSOCIAÇÃO ALEMÃ PARA EPIDERMÓLISE BOLHOSA. A criança com epidermólise bolhosa. I.E.B. Deutschland: Debra, s/d. (Apostila).

BALINT, M. O médico, seu paciente e a doença. Rio de Janeiro: Atheneu, 1988.

BOFF, L. Saber cuidar: ética do humano: compaixão pela terra. Petrópolis: Vozes, 1999.

BRAUN-FALCO, O.; PLEWIG, G.; WOLFF, H. H.; WINKELMANN, R.K. Dermatology. Berlin: Springer-Verlag, 1991.

CAPRARA, A. Uma abordagem hermenêutica da relação saúde-doença. Cad. Saúde Pública, v.19, n.4,

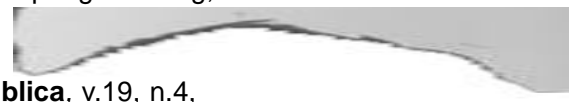
p.923-31, 2003.

CAPRARA, A.; SILVA FRANCO, A. L. A relação médico-paciente: para uma humanização da prática médica. Cad. Saúde Pública, v.15, n.3, p.647-54, 1999.

CAPRARA, A.; RODRIGUES, J. A relação assimétrica médico-paciente: repensando o vínculo terapêutico. 
Ciênc. Saúde Coletiva, v.9, n.1, p.139-46, 2004.

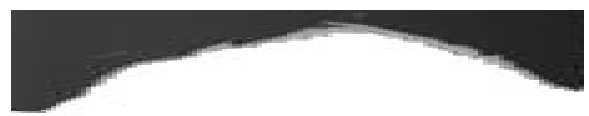

CZERESNIA, D. Do contágio à transmissão: ciência e cultura na gênese do conhecimento. Rio de Janeiro: Fiocruz, 1997.

DINIZ, A. B.; VIEIRA, L. A epidermólise bolhosa. Nursing - Rev. Téc. Enferm., v.8, n.94, p.16-20, 1995.

DREYFUS, H.L. Being in the world: a commentary on Heidegger's being and time. Cambridge: MIT Press, 1991.

DURHAM, E. Movimentos sociais: a construção da cidadania. São Paulo: Cebrap,1984. (Novos Estudos).

EADY, R. A. J. The classification of epidermolysis bullosa. In: PRIESTLEY, G. C.; TIDMAN, M. J.; WEISS, J. B.; EADY, R. A. J. (Orgs.) A comprehensive review of classification, management and laboratory studies. Growthom: Debra, 1990. p.1-9.

EKMAN, I.; EHNFORS, M.; NORBERG, A. The meaning of living with severe chronic hearth failure. Scand. J. Caring Sci., v.14, p.130-6, 2000.

FINE, J.D. The classification of inherited Epidermolysis Bullosa: current approach, pitfalls, unanswered questions, and future directions. In: FINE, J. D.; BAUER, E.A.; MCGUIRE, J.; MOSHELL, A. (Orgs.) Epidermolysis bullosa: clinical, epidemiologic and laboratory advances and the findings of the National Epidermolysis Bullosa Registry. Baltimore: The Johns Hopkins University Press, 1999. p.20-47.

FINE, J.D.; BAUER, E.A.; MCGUIRE, J.; MOSHELL, A. Epidermolysis bullosa: clinical, epidemiologic and laboratory advances and the findings of the National Epidermolysis Bullosa Registry. Baltimore: The Johns Hopkins University Press, 1999a.

FINE, J. D.; JOHNSON, L.B.; SUCHINDRAN, C.; CARTER, D. M.; MOSHELL, A. The National Epidermolysis Bullosa Registry: organization, goals, methodologic approaches, basic demography, and accomplishments. In: FINE, J. D.; BAUER, E.A.; MCGUIRE, J.; MOSHELL, A. (Orgs.) Epidermolysis bullosa: clinical, epidemiologic and laboratory advances and the findings of the National Epidermolysis Bullosa Registry. Baltimore: The Johns Hopkins University Press, 1999b . p.79-100.

GADAMER, H. G. Verdade e método. Petrópolis: Vozes, 1997.

GADAMER, H. G. Dove si nasconde la salute. Milano: Raffaello Cortina Editore, 1984.

GEANELLOS, R. Hermeneutic philosophy. Part I: implications of its use as methodology in interpretive nursing research. Nurs. Inq. Melbourne, v.5, p.154-63, 1998a.

GEANELLOS, R. Hermeneutic philosophy. Part II: a nursing research example of the hermeneutic imperative to address forestructures/pre-understandings. Nurs. Inq. Melbourne, v.5, p.238-47, 1998b.

GEANELLOS, R. Exploring Ricoeur's hermeneutic theory of interpretation as a method of analyzing research texts. Nurs. Inq., v. 7, p.112-9, 2000.

GEORGE, A. O. Epidermolysis bullosa, three cases in an African family: medical, social and economic problems in management in a developing country. Trop. Geogr. Med., v.40, v.2, p.171-73, 1988.

GOFFMAN, E. Stigma: l'identità negata. Milano: Giuffré Editore, 1983.

GOMES, R.; MENDONÇA, E. A.; PONTES, M. L. As representações sociais e a experiência da doença. Cad. Saúde Pública, v.18, n.5, p.1207-14, 2002.

HEIDEGGER, M. Ser e tempo. 4.ed. Petrópolis: Vozes,1993. (pt.2).

KLAFKE, T. E. O médico lidando com a morte; aspectos da relação médico-paciente terminal em cancerologia. In: CASSORIA, R. M. S. (Org.) Da morte: estudos brasileiros. Campinas: Papirus, 1991. p.51-78. 
KOURY, M. G. P. Uma fotografia desbotada: atitudes e rituais do luto e o objeto fotográfico. João Pessoa: Manufatura/GREM, 2002.

LANSDOWN, R.; ATHERTON, D.; DALE, A.; SPROSTON, S.; LLOYD, J. Practical and psychological problems for parents of children with epidermolysis bullosa. Child - care, health dev., v.12, n.4, p.251-6, 1986.

MARMOT, M.; WILKINSON, R. G. Social determinants of health. Oxford: Oxford University Press, 1999.

MISHLER, E. G. Research interviewing: context and narrative. Cambridge: Harvard University Press, 1986.

MORAIS, P. B. Discursos e interditos: a medicina frente a pacientes terminais de câncer. Fortaleza: Universidade de Fortaleza, 1997.

PINTO, T. M. Filosofia na enfermagem: algumas reflexões. Pelotas: UFPel, 1998.

RICOEUR, P. O conflito das interpretações. Rio de Janeiro: Imago, 1978.

RICOEUR, P. A metáfora viva. Porto: Rés Editora, 1983.

RICOEUR, P. From text to action: essays in hermeneutics II. London: The Athlone Press, 1991.

RICOEUR, P. Hermeneutics and the human sciences. Cambridge: Cambridge University Press, 1995.

ROBERTSON-MALT, S. Listening to them and reading me: a hermeneutic approach to understanding the experience of illness. J. Adv. Nurs., v.2, p.290-7, 1999.

SILVA, R. B. P.; RAMALHO, A. S. Riscos e benefícios da triagem genética: o traço falciforme como modelo de estudo em uma população brasileira. Cad. Saúde Pública, v.13., n.2, p.285-94, 1997.

SPINK, M. J.; MEDRADO, B. Produção de sentidos no cotidiano: abordagem teórico-metodológica para análise das práticas discursivas. In: SPINK, M. J. (Org.) Práticas discursivas e produção de sentidos no cotidiano: aproximações teóricas e metodológicas. São Paulo: Cortez, 1999. p.41-61.

TODRES, L.; WHEELER, S. The complementarity of phenomenology, hermeutics and existentialism as a philosophical perspective for nursing research. Int. J. Nurs. Res. Stud., v.38, p.1-8, 2001.

WIKLUND, L.; LINDHOLM, L.; LINDSTROM, U. A. Hermeneutics and narration: a way to deal with qualitative data. Nurs. Inq., v.9, n.2, p.114-25, 2002.

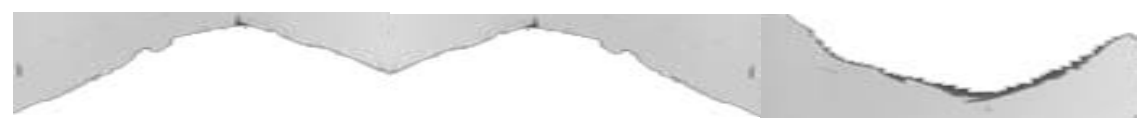

CAPRARA, A.; VERAS, M. S. C. Hermenéutica y narrativa: la experiencia de madres de niños afectados por EB, Interface - Comunic., Saúde, Educ., v.9, n.16, p.131-46, set.2004/ fev.2005.

El articulo analiza la narrativa de tres madres de niños afectados por Epidermolisis Bullosa (EB) con un abordaje inspirado en la hermenéutica fenomenológica de P. Ricoeur. La Epidermolisis Bullosa es una enfermedad severa y rara que se manifiesta principalmente en la piel y mucosa que, al ser afectadas, producen rupturas y sufrimiento a los niños portadores y a los familiares que los cuidan. La experiencia del sufrimiento, el estigma, el miedo del contagio, la relación con los profesionales de salud, particularmente con los médicos, y las prácticas de cuidado, son algunos de los temas analizados. El intercambio de experiencias promovido por las redes sociales puede proporcionar avances en la mejoría de la calidad de vida de los portadores de EB, además del apoyo social a los familiares $y$, por la expansión de estas redes, sensibilizar a los profesionales de la salud y a los gestores para que adopten políticas públicas más eficaces y equitativas.

PALABRAS CLAVE: Hermenéutica; análisis narrativa; epidermolysis bullosa. 